\title{
NONLINEAR MODEL OF THE PASSENGER CAR SEAT SUSPENSION SYSTEM
}

\author{
DANKO Ján ${ }^{1}$, MILESICH Tomáš ${ }^{1}$, BUCHA Jozef ${ }^{1}$ \\ ${ }^{1}$ Slovak University of Technology in Bratislava, Faculty of Mechanical Engineering, Institute of Transport \\ Technology and Designing, Nám. Slobody 17,812 31 Bratislava, Slovakia
}

\begin{abstract}
The paper deals with the modelling of a passenger car seat suspension system. Currently, vehicle safety and ride comfort are one of the most important factors of vehicle design. This article analyses a mathematical model of the passenger car seat suspension system. Furthermore, experimental measurements of the passenger car seat suspension system are performed. Utilizing the experimental data, model parameters are identified. From the chosen mathematical model a simulation model in constructed in Matlab is designed. In this simulation, the force-velocity and force-displacement characteristics of the passenger car seat suspension system are described. Finally, evaluation of simulated damper characteristics with the characteristics form measured data are performed.
\end{abstract}

KEYWORDS: Passenger car seat, comfort, suspension system, Spencer model.

\section{Influence of seat suspension system on driving comfort and driving safety}

Driving comfort and safety is one of the most important aspects of the drivers operating space. The seating position of driver and passengers can improve driving comfort. The suspension vehicle system includes springs and dampers. The seat can be analogous to a system of springs and dampers. Damping coefficient of the seat can be changed by the properties of foam materials utilized. Increasing driving comfort simultaneously increase active safety. Damping coefficient of material can be experimentally measured. Mathematical models and simulations of the seat result in more economical ways to design and simulate seat comfort.

\section{Impact of vibrations on the human body}

The effect of vibrations on the human body results in the forced oscillation of certain body segments or the body as a whole. It depends on the way the vibrations are transmitted. Also physical properties of the vibrations like intensity and frequency represent a dominant part of forces in oscillation. Some exciting frequencies can be near the natural frequency of the body and its segments. In fig. 1, values of human body natural frequencies can be observed, [4].

The vertical oscillation is an important parameter in vehicle comfort and safety. ISO 2631 standard evaluates the effects of vibration. This standard specifies the limits of effective acceleration values, depending on the time of impact and frequency of oscillation. It also defines decreased performance limits, reduction of comfort limits and health hazard limits, [5]. Decrease comfort limit is 3.15 times lower than the allowable limit. See fig. 2. 


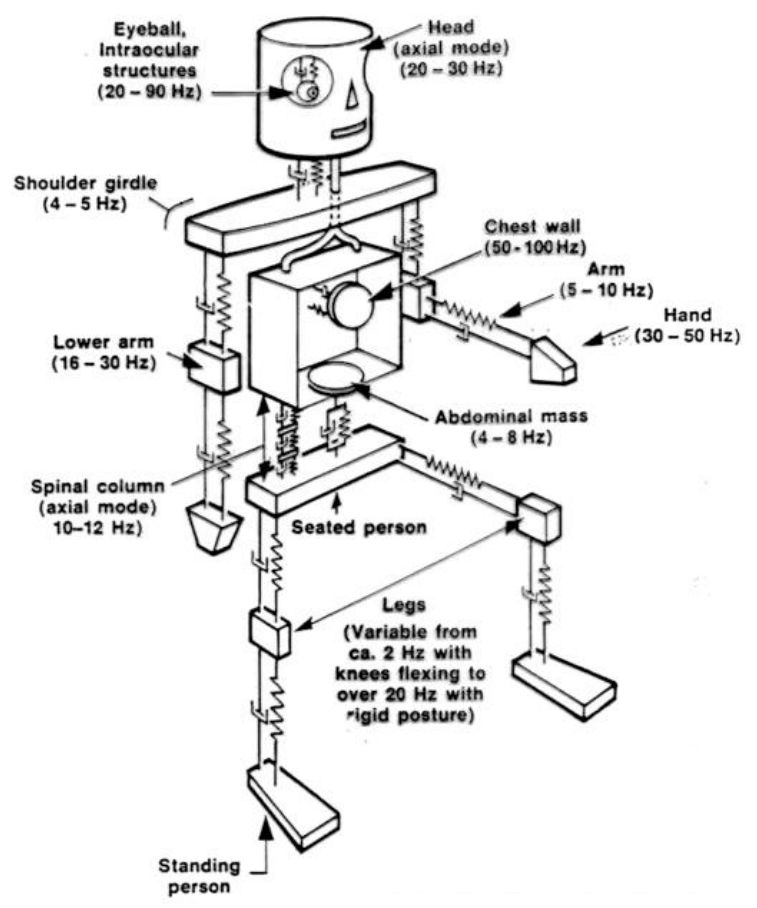

Fig. 1 Human body segment resonant frequencies, [1].

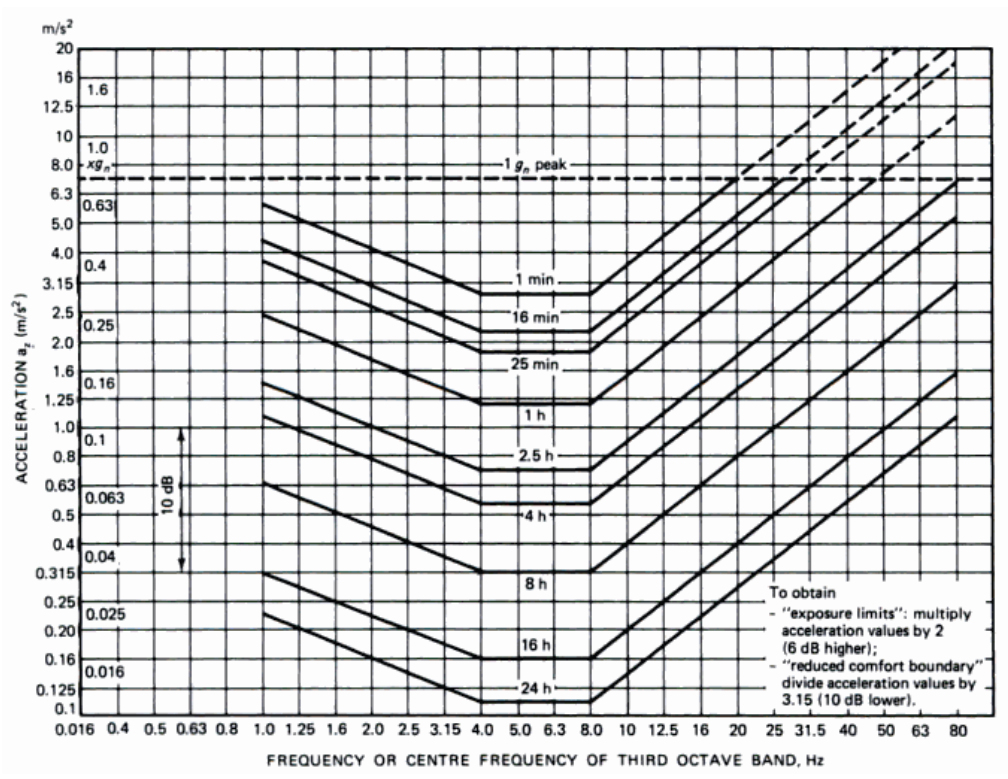

Fig. 2 ISO 2631, acceleration thresholds [1].

\section{Passenger car seat construction}

The typical construction of a car seat is a compromise between two contradictory requirements, fig. 3. The foam filling and suspension system have to be able to ensure a firm connection between the vehicle and driver, problematic zone being below $3 \mathrm{~Hz}-$ at lower frequencies. However the seat must also isolate the passenger from vibrations of increasing frequency. At the same time, the seat must ensure healthy posture of the driver and passengers. For the driver it is important to sit in the optimal forward direct field of vision. This aspect significantly affects active safety. 


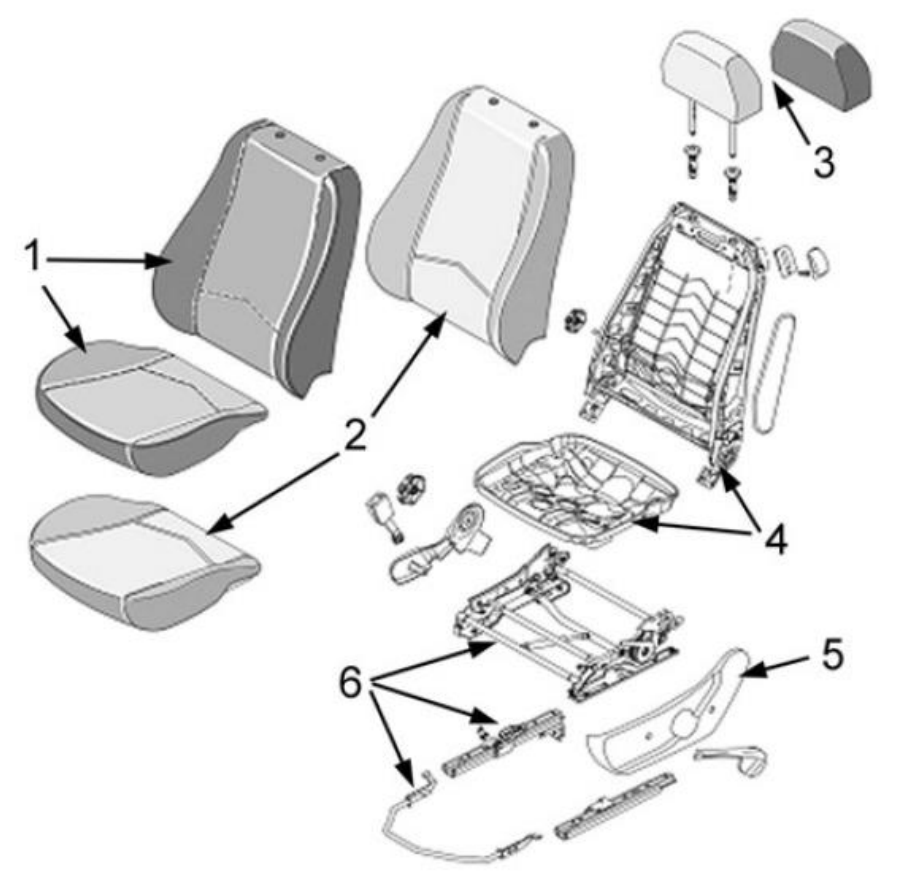

Fig. 3 Seat construction, 1- covers, 2 - foams, 3 - headrest, 4 - structure and suspension, 5 - plastic trim, 6 - interface structure between floor and mechanisms, slides, handle, [2].

\section{Measurement of passenger car seat suspension}

The experimental measurement was performed on a measurement test rig, test bed EDYZ 4 , which is a kinematic driver for car seats. The displacement was measured by potentiometer sensor and force was measured using strain gauges. The measurements were carried out according to the scheme in fig. 4 , which schematically shows the involvement of measuring input and output devices. Output PCI card generates a signal and sends it to a servovalve. Force response is measured by strain gauges. The signals from the potentiometer and strain gauges are recorded through the input card at PC2, which is processed in LabVIEW Signal Express [6], [7].

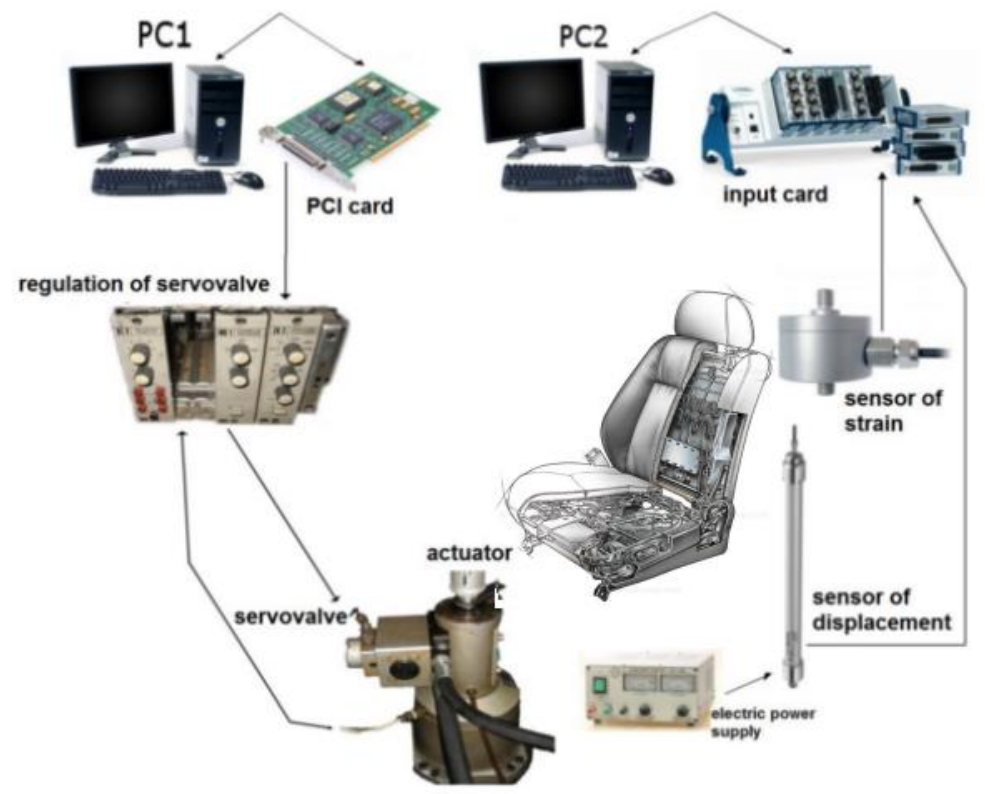

Fig. 4 Schematic model of the test rig. 


\section{$5 \quad$ Modelling of the virtual passenger car seat suspension}

The passenger car seat suspension is described by the Spencer mathematical model, Fig. 5, equations $(1,2,3)$ [3], and are implemented into MATLAB/Simulink, fig. 6.

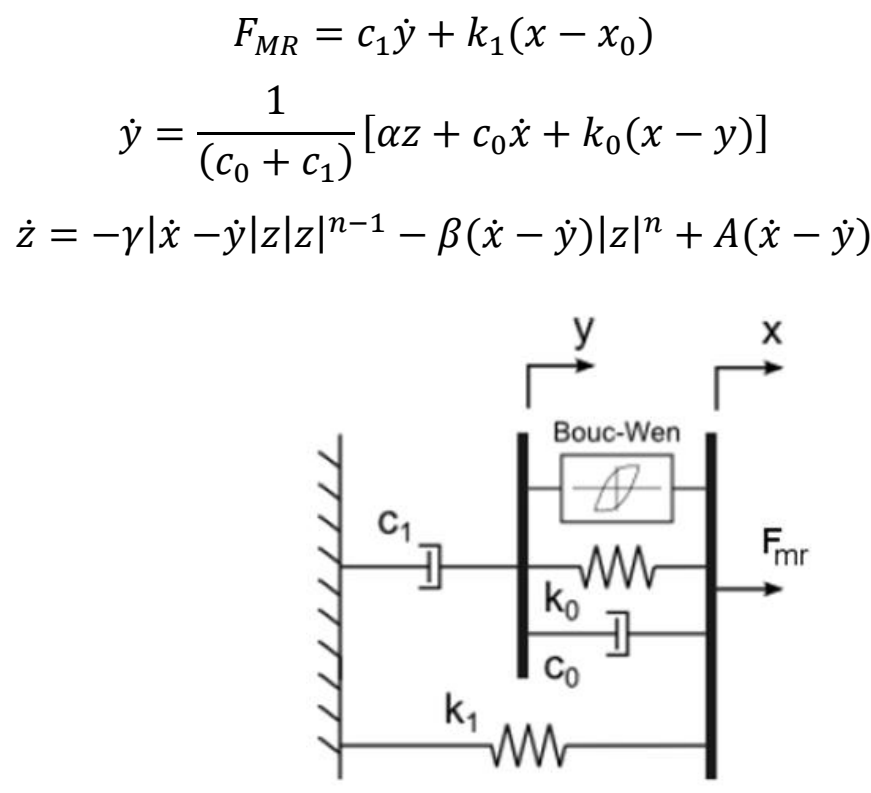

Fig. 5 Spencer mathematical model, [3].

Parameters $c_{0}$ and $c_{1}$ are coefficients of the viscous dampers. Parameters $k_{0}$ and $k_{1}$ are spring rates. Parameters $\dot{x}$ and $\dot{y}$ are velocities of the dampers. Parameter $x$ represents the deflection of the spring and $x o$ initial compression of the spring. Parameter $z$ is a variable of hysteresis and it is affected by parameters $\alpha, \beta, \gamma, n, A$. Parameters $\alpha, \beta, \gamma$ affect linearity during stretching and also the transition from compressed to extended state. Parameter $\alpha$ represent the stiffness of the damping force and is related to variable $z$. Parameter $n$ depends on the damping force and velocity [3].

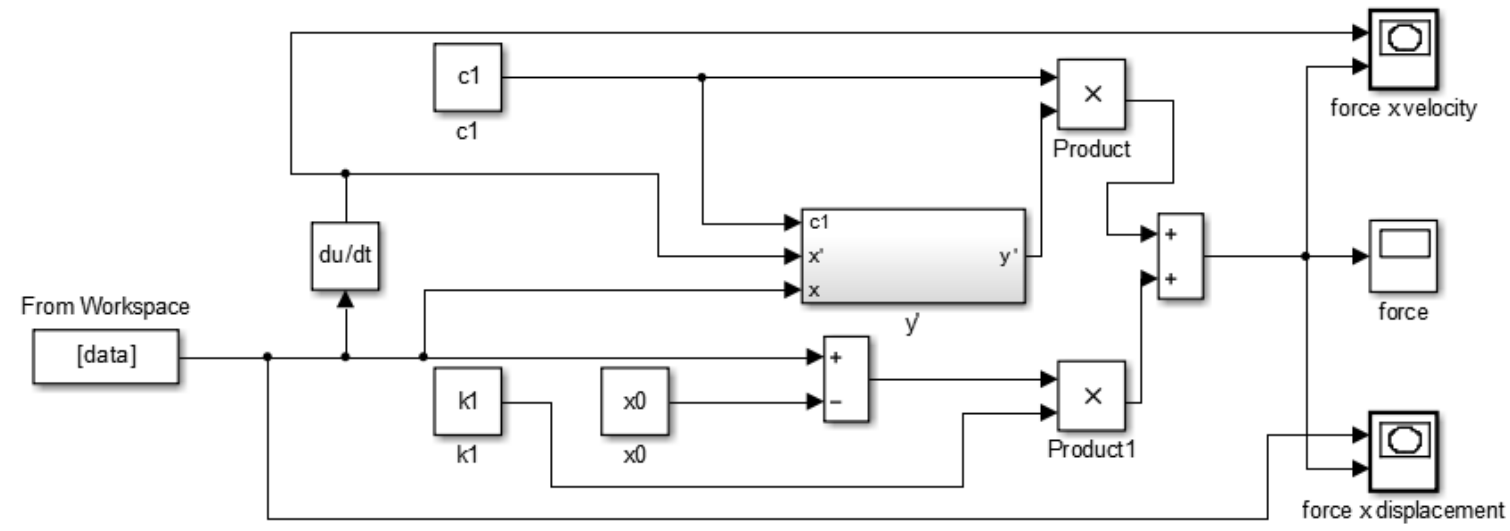

Fig. 6 Spencer model in MATLAB/Simulink. 


\section{Comparison of the modelled and measured data}

In the following figures, fig. 7 and fig. 8, the graphical comparison of measured and modelled characteristics of the seat are shown. As excitations of the Spencer model were used, parameters of equations were identified using the parameter estimation toolbox.

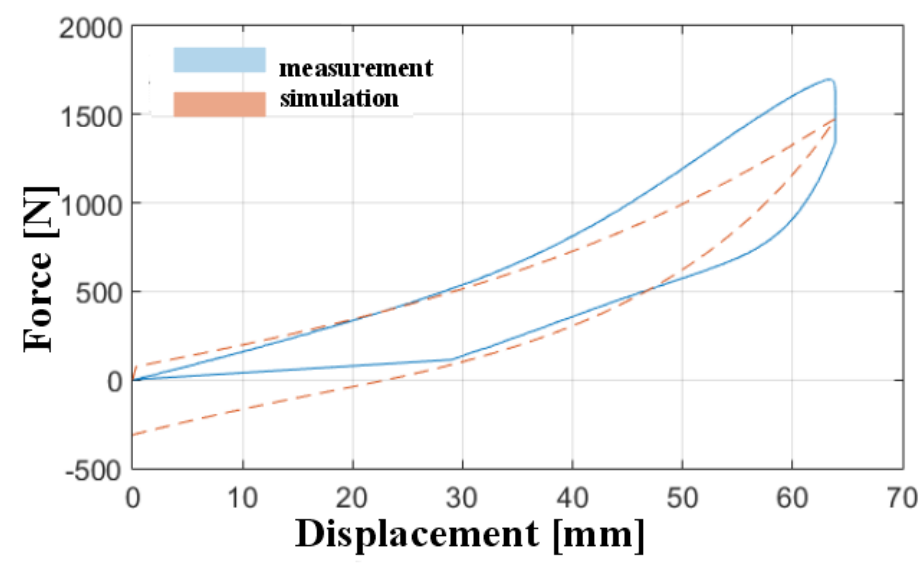

Fig. 7 Force - displacement characteristic.

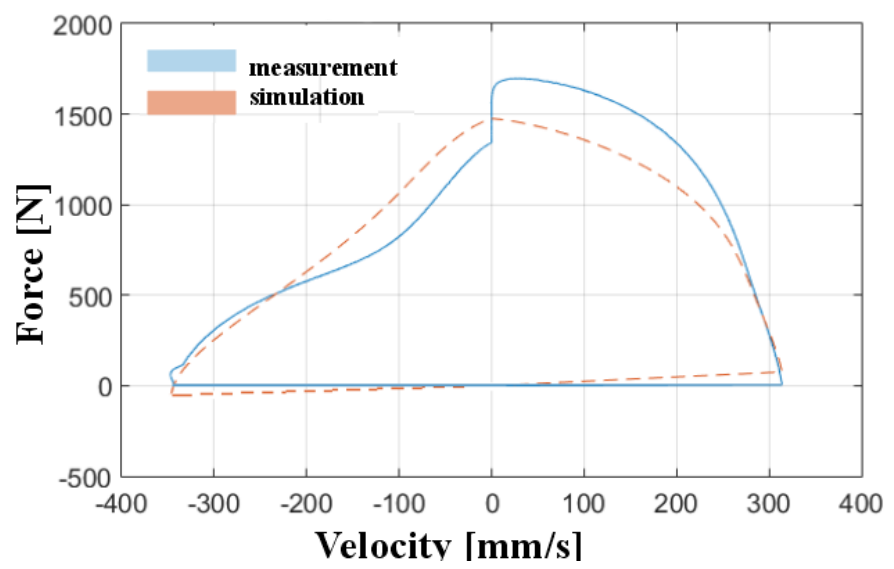

Fig. 8 Force - velocity characteristic.

\section{Conclusion}

The computer simulations significantly reduce the time needed to development and design the seat. Cost of properly constructed simulations is cheaper than manufacturing and testing of prototypes. The car seat is the only part of suspension that is in direct contact with the passengers. The measured data from experiment were used in a Matlab/Simulink model to tune the mathematical seat model. Simulation results were compared with experimentally measured values and correlate to approximately $86 \%$. More precise identification of the model parameters could result in a more accurate mathematical model, and should be the focus for further study. Also, using a more complex mathematical model could decrease errors between the simulation and experimental results. 


\section{REFERENCES}

[1] M. Ersoy, B. Heissing. Chassis Handbook: Fundamentals, Driving Dynamics, Components, Mechatronics, Perspectives. -Berlin: MercedesDruck, 2011. 616 p. ISBN 978-3-8348-0994-0

[2] L. Morello, L. Rossini, G. Pia, A. Tonolli. The automotive body, Volume 1: Components design. Springer, 2011, 665 p., ISBN 978-94-007-0513-5

[3] B. F. Spencer Jr., S. J. Dyke, M. K. Sain, J. D. Carlson. Phenomenological Model of a Magnetorheological Damper. Journal of Engineering Mechanics, 1997, 230-238. ISSN 0733-9399.

[4] M. J. Griffin, E.M. Whitman: Duration of whole-body vibration exposure: Its effect on comfort: Research report, 1976, 339 p.

[5] M. Pope, A. Magnusson. Guidelines for whole-body vibration health surveillance: Research report, 2002, 131 p.

[6] V. Ferencey, J. Madarás, M. Bugár. Modelling of Energy and Powertrain System of the Electric Vehicle. In: Transport Means 2012: 16th International Conference. Kaunas, Lithuania, October 25-26, 2012. Kaunas: University of Technology, 2012. 73 - 76. ISBN 1822-296X.

[7] R. Jančo, L. Écsi, P. Élesztős. FSW Numerical Simulation of Aluminium Plates by SYSWELD - Part II. Journal of Mechanical Engineering- Strojnícky časopis, 2016 (66), No. 2, 29 - 36., ISSN 2450-5471. 